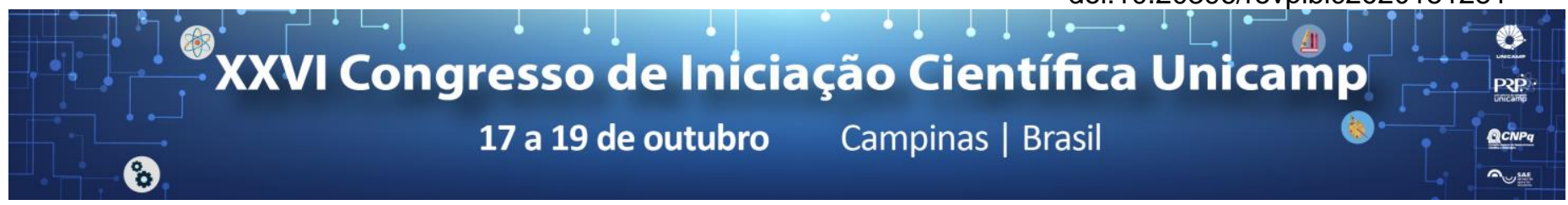

\title{
Avaliação de anestésicos tópicos para anestesia do freio lingual.
}

\section{Tamiris Christensen Bueno*, Jaiza S. M. de Araújo, Francisco C. Groppo, Maria C. Volpato.}

\section{Resumo}

A anquiloglossia é uma condição na qual há restrição da movimentação normal da língua dificultando a amamentação bebês e posteriormente, a fala. $O$ tratamento preconizado é a frenotomia, não havendo um consenso sobre a anestesia prévia ao procedimento. Este trabalho comparou, em voluntários adultos, a eficácia (taxa de sucesso e tempo de anestesia) dos anestésicos tópicos: mistura eutética de lidocaína 2,5\% e prilocaína 2,5\% (EMLA®), creme de lidocaína 4\% (Dermomax®), solução de tetracaína 1\% e fenilefrina 0,1\% (Allergan®) e um placebo, aplicados por 1 minuto dos dois lados do freio labial para determinar o de melhor escolha para realização de frenotomia em bebês. Todos os anestésicos testados foram melhores que o placebo em todos os níveis de pressão aplicados no freio lingual, porém as formulações Dermomax e EMLA apresentaram maior taxa de sucesso e tempo de anestesia que o Allergan. EMLA promoveu leve ardência durante a aplicação. Conclui-se que o Dermomax poderia ser a melhor escolha para aplicação em bebês.

\section{Palavras-chave:}

Anestesia tópica, Frenotomia, Anestésicos locais.

\section{Introdução}

A anquiloglossia é uma condição na qual há restrição da movimentação normal da língua, resultando em dificuldade de amamentação e lacerações nos mamilos da lactante, com consequente baixo ganho de peso do lactente e desistência do aleitamento materno (Srinivasan et al., 2006; Geddes et al., 2008). O tratamento preconizado é a frenotomia, realizada em bebês, com infiltração anestésica ou anestésico tópico ou, ainda, na ausência de anestesia local prévia. Até o momento não há um procedimento padrão de anestesia para este tipo de procedimento. Assim este estudo teve como objetivo avaliar anestésicos tópicos em adultos que apresentem melhor sucesso e tempo de anestesia, para uso em bebês.

\section{Resultados e Discussão}

O estudo foi caracterizado como randomizado, duplo cego, totalizando 4 sessões. De 43 voluntários, 40 foram submetidos á aplicação de um anestésico tópico (AT) por sessão, sendo eles: mistura eutética de lidocaína 2,5\% e prilocaína 2,5\% (EMLA®), creme de lidocaína 4\% (Dermomax®), solução de tetracaína $1 \%$ e fenilefrina $0,1 \%$ (Allergan $\AA$ ) e placebo (hidrogel de carbopol). Foram aplicados $62,5 \mathrm{mg}$ de EMLA e Dermomax e 1 gota de Allergan de cada lado do freio lingual, durante 1 minuto. A percepção dolorosa do freio lingual foi avaliada por aplicação de pressão com 0 aparelho Von Frey. Previamente à aplicação dos ATs foi avaliada a sensibilidade basal dos voluntários ao von Frey.

Todas as formulações testadas foram melhores que o placebo em todos os níveis de pressão aplicados acima do basal $(20 \%, 30 \%, 50 \%, 70 \%, 90 \%$ e $100 \%$ - Fig. 1$)$. Dermomax e EMLA foram mais eficazes que o Allergan. Nas pressões menores (20\% e $30 \%$ ) o Dermomax foi mais eficaz que o EMLA.

Um voluntário desistiu do estudo e duas não foram submetidas à avaliação por apresentarem ausência de dor à aplicação de pressão pelo von Frey (avaliação basal) na intensidade máxima estabelecida $(100 \mathrm{~g})$. Os voluntários relataram leve ardência com a aplicação do EMLA.

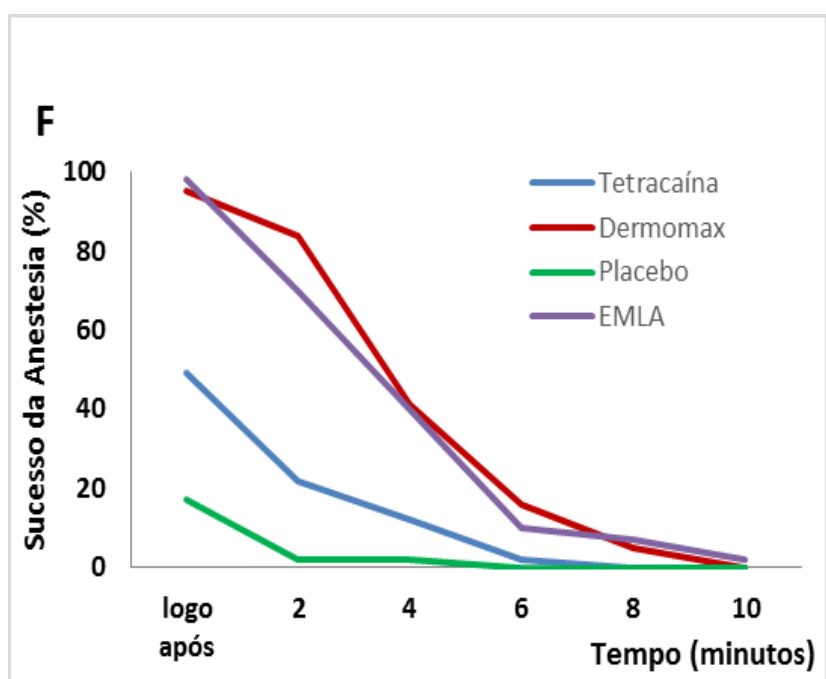

Figura 1. Porcentagem de indivíduos apresentando anestesia do freio labial, ao longo do tempo, após aplicação de Tetracaína, Dermomax, Placebo e EMLA, durante 1 minuto. Sucesso da anestesia: ausência de percepção de dor com aplicação de força em intensidade $100 \%$ acima do valor basal do voluntário.

\section{Conclusões}

Todos os anestésicos testados foram mais eficazes que o placebo em todos os níveis de pressão aplicados no freio lingual, porém as formulações Dermomax e EMLA apresentaram maior taxa de sucesso e tempo de anestesia. Por proporcionar maior sucesso que o EMLA nas pressões menores e não provocar ardência, 0 Dermomax pode ser o anestésico de escolha em bebês.

\section{Agradecimentos}

Aos voluntários que participaram do estudo e ao $\mathrm{CNPq}$ pela concessão da bolsa (800295/2016-1).

Srinivasan A, Dobrich C, Mitnick H, Feldman P. Ankyloglossia in breastfeeding infants: the effect of frenotomy on maternal nipple pain and latch. Breastfeed Med 2006; 1: 216-24.

Geddes DT, Langton DB, Gollow I, Jacobs LA, Hartmann PE, Simmer K. Frenulotomy for breastfeeding infants with ankyloglossia: effect on milk removal and sucking mechanism as imaged by ultrasound. Pediatrics 2008; 122: e188-94. 